\title{
Correction to: Mediastinal fluid as a predictor for esophageal perforation as the cause of pneumomediastinum
}

\section{Cletus Fuhrmann ${ }^{1} \cdot$ Matthew Weissenborn ${ }^{2} \cdot$ Sehar Salman $^{3}$}

Published online: 10 September 2020

(C) American Society of Emergency Radiology 2020

Correction to: Emergency Radiology (2020) https://doi.org/10.1007/s10140-020-01841-x

In the original version of this paper contains an error in author name. Sehan Selmar has been corrected to Sehar Salman. The Original article has been corrected.

\section{Compliance with ethical standards}

Conflict of interest The authors declare that they have no conflict of interest.

Publisher's note Springer Nature remains neutral with regard to jurisdictional claims in published maps and institutional affiliations.

The online version of the original article can be found at https://oi.org/ 10.1007/s10140-020-01841-x

Cletus Fuhrmann

fuhrmann.cletus@gmail.com

Baylor University Medical Center at Dallas, Dallas, TX 75246, USA

2 Baylor University Medical Center at Dallas, American Radiology Associates, Dallas, TX 75246, USA

3 Texas A\&M College of Medicine, Bryan, TX 77807, USA 